\title{
Changes in thymidylate synthase and its inhibition rate and changes in dihydropyrimidine dehydrogenase after the administration of 5-fluorouracil with cisplatin to nude mice with gastric cancer xenograft SC-1-NU
}

\author{
Yoichi Sakurai, Takashi Uraguchi, Hiroki Imazu, Shigeru Hasegawa, Toshiki Matsubara, Masahiro Ochiai, \\ and TAKAHIKO FUNABIKI
}

Department of Surgery, Fujita Health University School of Medicine, 1-98 Dengakugakubo, Kutsukake-cho, Toyoake, Aichi 470-1192, Japan

\begin{abstract}
Background. Although 5-fluorouracil (5-FU) and cisdiamminedichloroplatinum (cisplatin) in combination have synergistic cytotoxicity against both murine and human neoplasms, the precise mechanism of the synergism, and the effects on thymidylate synthase and its percent inhibition, and the effects on dihydropyrimidine dehydrogenase (DPD) remained to be elucidated.

Methods. Experimental chemotherapy was performed using SC-1-NU, a human gastric carcinoma xenograft. SC-1-NU was maintained by serial transplantation in male $B A L B / c$ nude mice. The nude mice received various chemotherapeutic regimens consisting of $\mathbf{5 - F U}$ and/or cisplatin, with different dosages and periods of administration. After the treatment, we examined the in vivo effects of 5-FU and cisplatin in each regimen on thymidylate synthase and its percent inhibition, and the effects on DPD, in addition to the observation of tumor growth inhibition.

Results. The combined use of $5-F U(20 \mathrm{mg} / \mathrm{kg}$ per day) and cisplatin (either 1.5 or $7.5 \mathrm{mg} / \mathrm{kg}$ per day) showed a synergistic antitumor effect, regardless of the different doses of cisplatin. The long-term administration of 5-FU significantly increased both total thymidylate synthase and the percent thymidylate synthase inhibition rate. The short-term administration of 5FU significantly decreased DPD. Nevertheless, these changes showed no relation to the combined use of cisplatin.

Conclusion. Combined administration of cisplatin with 5-FU did not further increase thymidylate synthase inhibition over that occurring with 5-FU alone, which does not support the hypothesis that cisplatin combined with 5-FU modulates thymidylate synthase inhibition in enhancing the anticancer effect of 5-FU. Changes in DPD after the administration of 5FU may provide an insight into tumor sensitivity and resistance to 5-FU.
\end{abstract}

Key words 5-Fluorouracil - Cisplatin · Nude mice · Gastric cancer - Thymidylate synthase - Dihydropyrimidine dehydrogenase

Offprint requests to: Y. Sakurai

Received: July 31, 2003 / Accepted: March 11, 2004
Introduction

Combined administration of 5-fluorouracil (5-FU) with cis-diamminedichloroplatinum (cisplatin) has been shown to elicit synergistic cytotoxicity against both murine and human neoplasms [1,2]. Although 5-FU is one of the anticancer agents employed as a single agent for advanced gastric cancers, response rates with single agents such as 5-FU, mitomycin, doxorubicin, epirubicin, and cisplatin are reported to be $20 \%-30 \%$ [3]. 5-FU combined with cisplatin has been used clinically to increase efficacy, and recent clinical data have shown the synergistic effects of cisplatin with 5-FU in patients with gastrointestinal cancers [4-6] and other types of cancers, including head and neck cancers [2,79]. Although the mechanism of the synergistic effect has been debated for years [10,11], it has been demonstrated, in vitro, that cisplatin works as a biomodulator of the effect of 5-FU by increasing the availability of reduced folate, which may result in an increase in thymidylate synthase (TS) inhibition [10]. However, direct evidence of enhanced TS inhibition in human cancers has not been available. Furthermore, differences in TS and its inhibition between various modes of administration of cisplatin have not been established.

Resistance to anticancer agents is one of the important mechanisms responsible for an unsatisfactory clinical outcome in patients with gastric cancers. Recently, it has been demonstrated that sensitivity to 5-FU is significantly correlated with TS [12] and/or dihydropyrimidine dehydrogenase (DPD) [13]. TS plays a key role in DNA nucleotide precursor synthesis and represents an important therapeutic target for 5-FU [14]. DPD is a primary enzyme that metabolizes 5-FU [15]. However, changes in TS and DPD after treatment with 5-FU and cisplatin have not been well documented.

In the present study, we examined changes in TS, TS inhibition, and DPD after the administration of 5-FU or cisplatin alone, and in combination, using a human gas- 
tric cancer xenograft, SC-1-NU, transplanted in nude mice.

\section{Materials and methods}

\section{Experimental animals and human tumor xenografts}

$\mathrm{BALB} / \mathrm{c}$ male nude mice, obtained from Clea Japan (Tokyo, Japan), were maintained under specific pathogen-free conditions at the Animal Center of the Joint Research Laboratory, Fujita Health University. The human stomach carcinoma xenograft, SC-1-NU (poorly differentiated adenocarcinoma), was serially transplanted in nude mice by inoculating tumor fragments, measuring $3 \times 3 \times 3 \mathrm{~mm}$, subcutaneously in the dorsum of the nude mice, using a trocar needle. SC-1NU, established at the Second Department of Surgery, Nagoya University School of Medicine, was kindly gifted by Dr. Kubota, at the Department of Surgery, Keio University School of Medicine. SC-1-NU is relatively sensitive to 5-FU [16]. We randomly checked the histological integrity of tumors to ensure that the histology of the tumor was consistently preserved.

\section{Anticancer chemotherapy protocol}

The nude mice were assigned to six experimental groups. Eight mice $(n=8)$ were used for each experimental group. 5-FU was kindly gifted by Kyowa Hakko (Tokyo, Japan). Cisplatin was purchased from Nippon Kayaku (Tokyo, Japan). Each chemotherapeutic regimen is summarized in Fig. 1. Group A $(n=8)$ received saline as a control group. Group B $(n=8)$ received 5FU $(20 \mathrm{mg} / \mathrm{kg})$ daily, 5 days per week. Groups C $(n=8)$ and $\mathrm{E}(n=8)$ received cisplatin alone; group $\mathrm{C}$ received $1.5 \mathrm{mg} / \mathrm{kg}$ cisplatin daily on 5 consecutive days per week, and group E received $7.5 \mathrm{mg} / \mathrm{kg}$ as a bolus, once per week. Groups $\mathrm{D}(n=8)$ and $\mathrm{F}(n=8)$ received a combination of 5-FU and cisplatin. Group D received $20 \mathrm{mg} / \mathrm{kg}$ of $5-\mathrm{FU}$ and $1.5 \mathrm{mg} / \mathrm{kg}$ of cisplatin daily, on 5 consecutive days per week. Group F received $20 \mathrm{mg} / \mathrm{kg}$ of 5-FU daily on 5 consecutive days per week and $7.5 \mathrm{mg} / \mathrm{kg}$ of cisplatin as a bolus, once per week. These chemotherapeutic regimens were performed for either 1 week as a short-term experiment, or for at least 4 weeks as a long-term experiment. After completion of the chemotherapeutic regimens, the mice were killed by cervical dislocation; the tumors were excised immediately and then stored at $-80^{\circ} \mathrm{C}$ until analyses.

Evaluation of tumor weight, relative tumor weight, and relative tumor-free body weight

The size of the tumor was measured with sliding calipers three times per week by the same observer. The esti-
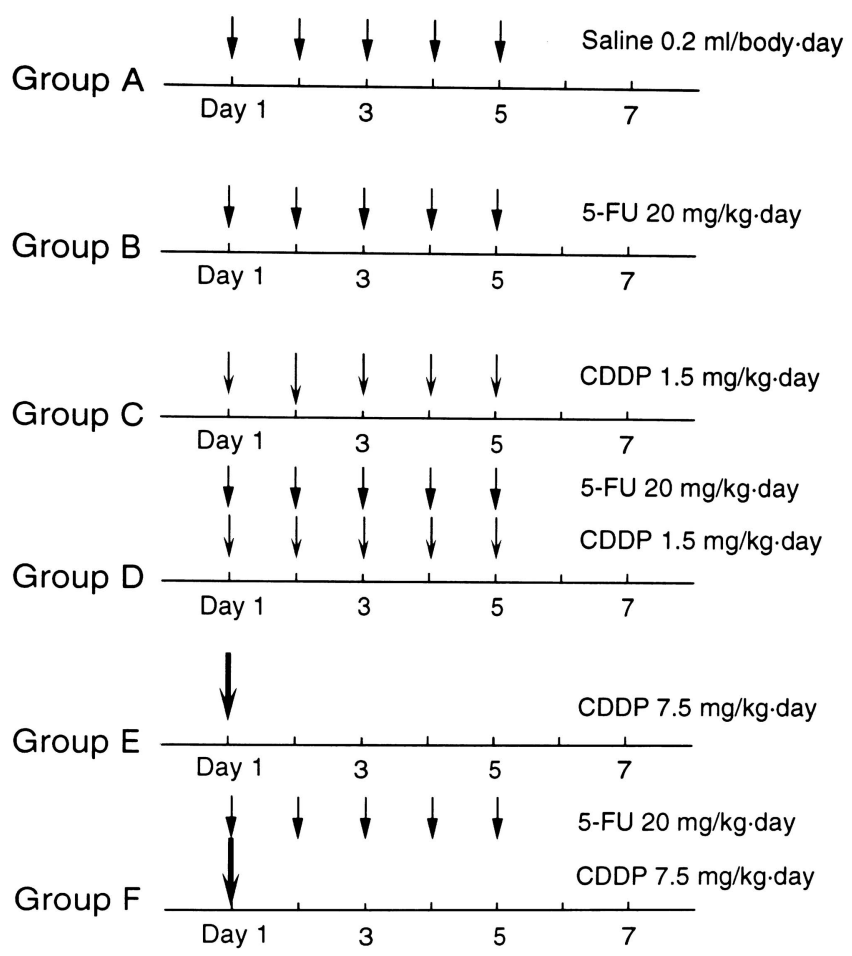

Fig. 1. Experimental protocol of each group. Group A received saline (controls); group B received $20 \mathrm{mg} / \mathrm{kg}$ of 5 fluorouracil $(5-F U)$ alone daily on 5 days per week; group $\mathrm{C}$ received intermittent cisplatin $(C D D P)$ alone at $1.5 \mathrm{mg} / \mathrm{kg}$ five times per week; group D received $20 \mathrm{mg} / \mathrm{kg} 5$-FU plus cisplatin at $1.5 \mathrm{mg} / \mathrm{kg}$ daily five times per week; group E received cisplatin alone at $7.5 \mathrm{mg} / \mathrm{kg}$ once per week; and group F received $20 \mathrm{mg} / \mathrm{kg}$ of 5 -FU on 5 consecutive days per week plus cisplatin $7.5 \mathrm{mg} / \mathrm{kg}$ once per week

mated tumor weight (ETW) was calculated using the method described by Geran et al. [17], that is:

$\operatorname{ETW}(\mathrm{mg})=\frac{\mathrm{L}(\mathrm{mm}) \times(\mathrm{W}(\mathrm{mm}))^{2}}{2}$

where $\mathrm{L}$ is the length and $\mathrm{W}$ is the width of the tumor. When the ETW reached 100 to $300 \mathrm{mg}$, the mice were assigned to the six experimental groups. The relative tumor weight (RTW) was calculated, for the evaluation of the treatments, as follows:

$\mathrm{RTW}=\frac{\mathrm{Wi}}{\mathrm{W} 0}$

where Wi is the mean ETW at each time point and W0 is the mean ETW at the start of the treatment. The antitumor effects were evaluated by growth curves and the treatment/control (T/C) ratio (\%) at the end of the treatment, that is:

$\mathrm{T} / \mathrm{C}$ ratio $=\frac{\mathrm{RTWt}}{\mathrm{RTWc}}$ 
where RTWt is the mean RTW at the end of the treatment in the treated group and RTWc is the mean RTW in the control group. A positive antitumor effect was defined by the $\mathrm{T} / \mathrm{C}$ ratio being equal to or less than 0.42 , which was derived from the fact that each diameter of the dimension of the tumor regressed less than $75 \%$. The total body weight (TBW) of the mice was also measured, three times per week. The tumor-free body weight (TFBW) was calculated by subtracting the ETW from the TBW. Relative tumor-free body weight was calculated as follows:

$$
\text { Relative TFBW }=\frac{\text { TFBWt }}{\text { TFBWc }}
$$

where TFBWt is the mean TFBW at the end of the treatment in the treated group and TFBWc is the mean RTW in the control group.

When the chemotherapeutic regimens were completed, the mice were killed and the entire tumors were resected within $8 \mathrm{~h}$ after the final dose of the agents. The tumors were immediately fixed in paraformaldehyde for $12 \mathrm{~h}$ and embedded in paraffin for further analyses.

\section{Calculation of necrosis index}

The necrosis index of the tumor was calculated using a histological specimen of the tumor stained by H\&E. The necrosis index was defined as the necrotic area as a percentage of the entire tumor area.

\section{Measurement of thymidylate synthase (TS) in tumor tissue}

Thymidylate synthase (TS) in tumor tissue was measured by the method originally described by Spears et al. $[18,19]$, with some modifications. Briefly, tissue samples $(500 \mathrm{mg})$ were homogenized in citidine monophosphate (CMP) buffer ( $\mathrm{pH}$ 7.4) containing 2mercaptoethanol and they were centrifuged to isolate the cytosol fraction of the samples. Then, the cytosol fraction isolated was mixed with 2-mercaptoethanolcontaining buffer at $\mathrm{pH} 8.1$ and incubated at $25^{\circ} \mathrm{C}$ for $3 \mathrm{~h}$. The samples were mixed with $\left[{ }^{3} \mathrm{H}\right] 5$-fluoro-2'deoxyuridine-5'-monophosphate (FdUMP- $\mathrm{FH}_{4}$-bovine serum albumin [BSA]) reaction fluid and the mixture was incubated at room temperature for $20 \mathrm{~min}$. After the addition of dextran coated chacoal (DCC) solution, the radioactivity of the supernatant was measured with a liquid scintillation counter to determine the total TS activity. The TS activity was determined by comparing the radioactivity with those of standard samples. The apparent free TS was measured by mixing the supernatant with 2-mercaptoethanol-containing buffer at $\mathrm{pH}$
8.1, immediately followed by the addition of reaction fluid, without incubation. The apparent free TS was determined by the radioactivity. Free TS was determined as follows:

$$
\text { Free TS }=(\text { apparent free TS }-0.13 \times \text { total TS }) / 0.87
$$

TS inhibition rate $(\%)=(1-$ free $\mathrm{TS} /$ total TS $) \times 100$

\section{Measurement of DPD in tumor tissue}

DPD in tumor tissues was measured using the method described by Diasio et al. [20]. Briefly, the tumor tissues were homogenized with $20 \mathrm{mM}$ phosphate buffer including ethylene diamine tetraacetic acid (EDTA) and $1 \mathrm{mM} 2$-mercaptoethanol. After centrifugation, an enzyme immunoassay was performed, using 5-[6- $\left.{ }^{3} \mathrm{H}\right]$ fluorouracil as a substrate. Dihydrofluorouracil, $\alpha$ fluoro- $\beta$-uredopropionic acid, and $\alpha$-fluoro- $\beta$-alanine, derived by an enzyme action, were measured by HPLC. Part of the tissue homogenate was used for the measurement of protein concentration, and the DPD content was expressed as $\mathrm{pmol} / \mathrm{min}$ per $\mathrm{mg}$ protein.

\section{Statistical analysis}

Statistical significance was evaluated by Student's $t$-test. $P<0.05$ was considered statistically significant.

\section{Results}

The growth curves of the gastric cancer xenograft during the long-term chemotherapeutic regimen are shown in Fig. 2. The combined use of 5-FU ( $20 \mathrm{mg} / \mathrm{kg}$ per day) and cisplatin (either 1.5 or $7.5 \mathrm{mg} / \mathrm{kg}$ per day) showed a synergistic antitumor effect, regardless of the different doses of cisplatin (Fig. 2). The growth curves of group D and group F were similar (Fig. 2); the T/C ratios 7 days and 25 days after the start of the treatments are summarized in Fig. 3. Tumor growth was most effectively inhibited with the combined administration of 5-FU and cisplatin, and the lowest $\mathrm{T} / \mathrm{C}$ ratios, in groups $\mathrm{D}$ and $\mathrm{F}$, were apparent at 25 days after the start of the treatment. There was no difference in the $\mathrm{T} / \mathrm{C}$ ratios between group $\mathrm{D}$ and group $\mathrm{F}$ at either 7 days or 25 days after the start of the treatment (Fig. 3).

Changes in the TFBW during the regimens are summarized in Fig. 4. The TFBW in group D was the lowest for the entire treatment period, but the difference from the other experimental groups was not statistically significant. There was no difference in TFBW during the course of the treatment between any experimental groups. 


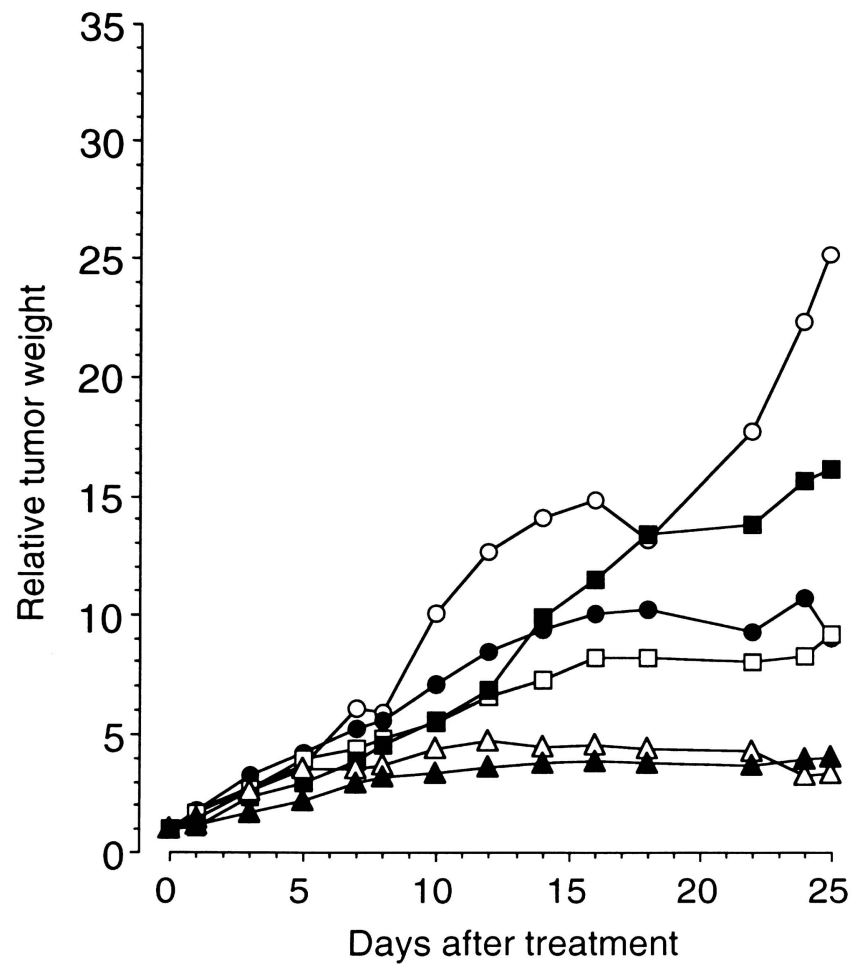

Fig. 2. Growth curves of SC-1-NU xenografts in nude mice during long-term chemotherapy in each experimental group. The data values are expressed as relative tumor weight (RTW). Open circles, group A; closed circles, group B; open squares, group $\mathrm{C}$; open triangles, group $\mathrm{D}$; closed squares, group $\mathrm{E} ;$ closed triangles, group $\mathrm{F}$

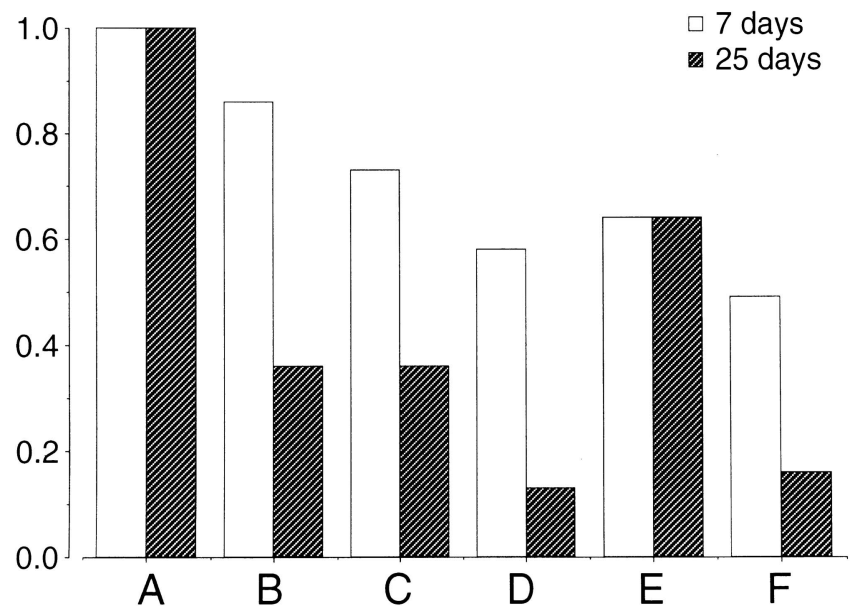

Fig. 3. Tumor/control (T/C) ratios in each experimental group. Data values were obtained on days 7 and 25 after the start of the chemotherapeutic regimens. $A-F$, groups A to $\mathrm{F}$

The necrosis indices of each experimental group are shown in Fig. 5. The necrosis index values after the longterm treatment were all higher than those after the short-term treatments in all of the experimental groups.

Total TS, free TS, and the percent TS inhibition rate of the gastric cancer xenograft after the short-term and

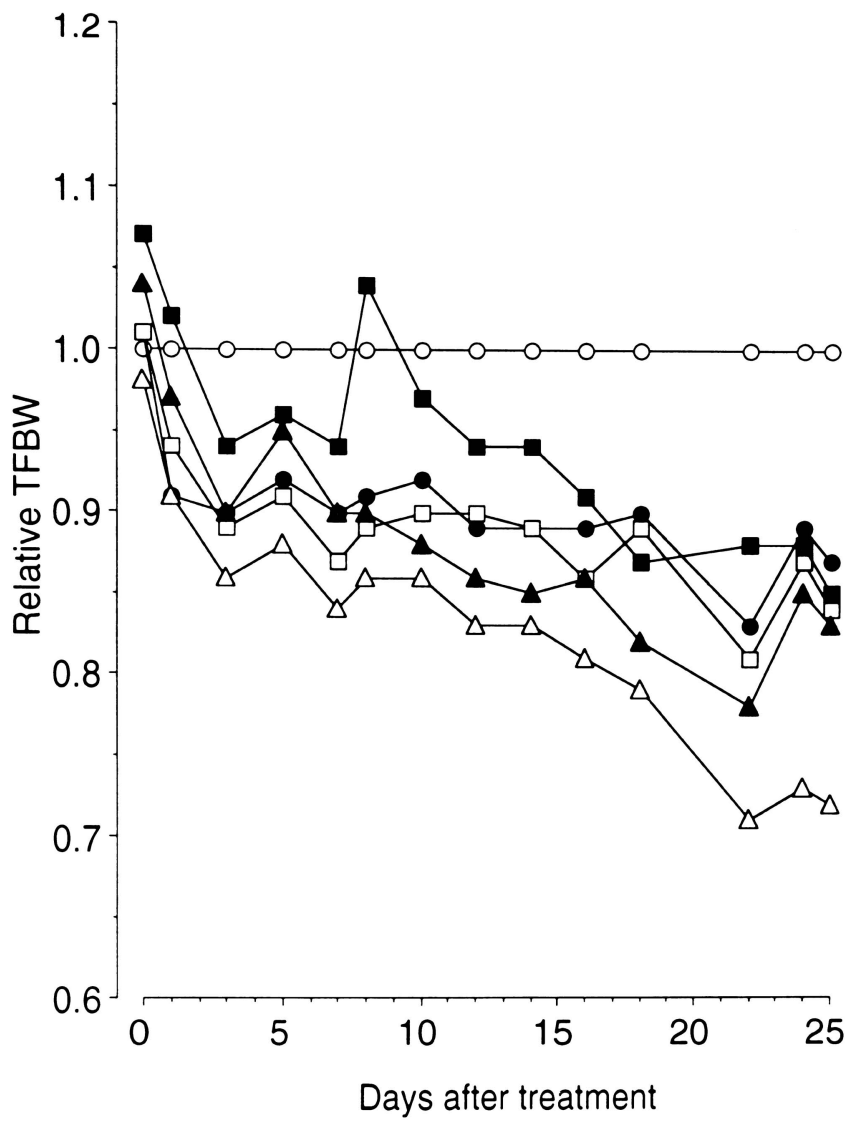

Fig. 4. Relative tumor-free body weight $(T F B W)$ of each experimental group. The data values are expressed as the mean values relative to those of the control group (group A). Symbols, as in Fig. 2

long-term treatments are summarized in Table 1. The total TS and the free TS after the short-term treatment were all higher than those after the long-term treatment in all of the experimental groups. The total TS and the percent TS inhibition rate in groups $\mathrm{B}, \mathrm{D}$, and $\mathrm{F}$ were significantly higher than those in group A after the longterm administration of the anticancer agents.

DPD values after the short-term anticancer chemotherapy are summarized in Table 2. DPD values in groups $\mathrm{B}, \mathrm{D}$, and $\mathrm{F}$ (the groups with 5-FU administration, with or without cisplatin) were significantly lower that in group A.

\section{Discussion}

The primary aim of the present study was to test whether the synergistic effect of 5-FU with cisplatin was attributable to changes in the percent TS inhibition rate and changes in DPD. The results of the present study demonstrated that the percent TS inhibition rates of 5FU plus cisplatin were not further increased compared 


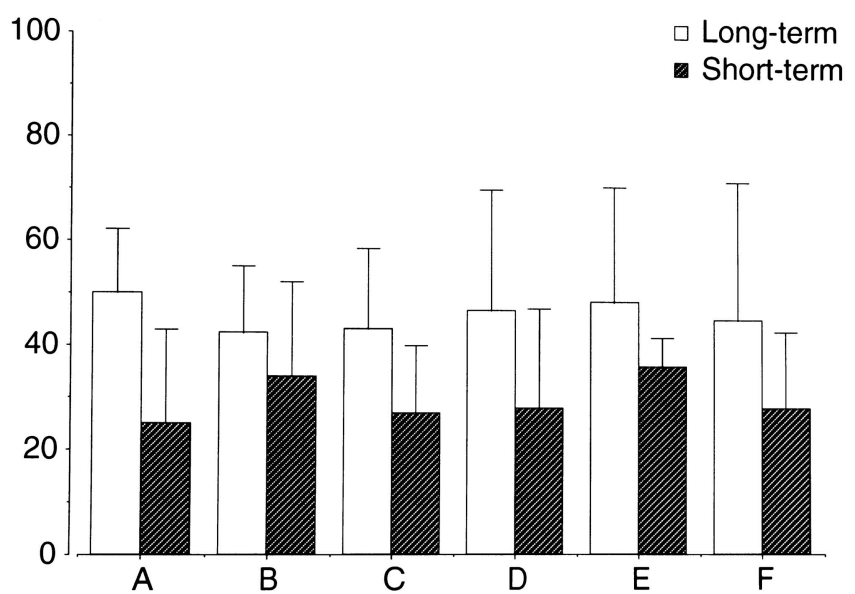

Fig. 5. Necrosis index of each experimental group. Data values were obtained on days 7 and 25 after the start of the experimental chemotherapy. The data values are expressed as means \pm SDs. $A-F$, groups A to $\mathrm{F}$ with that of 5-FU alone, regardless of the method of administration of cisplatin. While DPD in the shortterm administration of 5-FU was significantly decreased compared with the control value, DPD values in the groups with 5-FU plus cisplatin were not different from that in the group with 5-FU alone. These results suggest that, regardless of whether cisplatin was given as a bolus dose or intermittently, the administration of cisplatin had no effects on TS, TS inhibition, or DPD. Thus, the synergistic anticancer effect of 5-FU with cisplatin may be explained by mechanisms other than an increase in the percent TS inhibition rate and/or DPD.

However, it has been reported that the synergistic effect of 5-FU with cisplatin is explained by a further increase in the percent TS inhibition rate. The mechanism responsible for the increase in the TS inhibition rate is reported to be an increase in the 5,10-methylene tetrahydrofolic acid $\left(\mathrm{CH}_{2} \mathrm{FH}_{4}\right)$ pool caused by the decreased methionine uptake induced by cisplatin [10]. This notion is supported by Shirasaka et al. [11], who demonstrated that a reduced folate pool, of both $\mathrm{CH}_{2} \mathrm{FH}_{4}$ and $\mathrm{FH}_{4}$, increased after the intraperitoneal

Table 1. TS activities in tumor in each experimental group after long-term and short-term anticancer chemotherapy in nude mice with SC-1-NU xenograft

\begin{tabular}{|c|c|c|c|c|c|c|}
\hline & \multicolumn{6}{|c|}{ Experimental group } \\
\hline & $\begin{array}{l}\text { Group A } \\
\text { (control) }\end{array}$ & $\begin{array}{c}\text { Group B } \\
\text { (5-FU alone) }\end{array}$ & $\begin{array}{c}\text { Group C } \\
\text { (cisplatin alone) }^{\mathrm{a}}\end{array}$ & $\begin{array}{c}\text { Group D } \\
(5-\mathrm{FU}+\text { cisplatin })^{\mathrm{a}}\end{array}$ & $\begin{array}{c}\text { Group E } \\
{\text { (cisplatin alone })^{\mathrm{b}}}^{\text {(cin }}\end{array}$ & $\begin{array}{c}\text { Group } F \\
(5-F U+\text { cisplatin })^{b}\end{array}$ \\
\hline \multicolumn{7}{|l|}{ Long-term } \\
\hline Total TS & $8.5 \pm 4.9$ & $27.1 \pm 0.1 *$ & $5.4 \pm 0.0$ & $18.8 \pm 4.4^{*}$ & $19.1 \pm 0.0$ & $23.2 \pm 2.0 *$ \\
\hline Free TS & $8.0 \pm 5.0$ & $13.2 \pm 0.1$ & $5.1 \pm 0.0$ & $10.8 \pm 3.7$ & $18.0 \pm 0.0$ & $12.7 \pm 4.5$ \\
\hline \% TSIR & $10.4 \pm 15.3$ & $51.5 \pm 0.5^{*}$ & $5.6 \pm 0.0$ & $43.4 \pm 8.0^{*}$ & $5.8 \pm 0.0$ & $44.0 \pm 24.6^{*}$ \\
\hline \multicolumn{7}{|l|}{ Short-term } \\
\hline Total TS & $44.6 \pm 24.4$ & $78.7 \pm 44.1$ & $44.0 \pm 34.0$ & $106.2 \pm 18.8^{*}$ & $38.6 \pm 24.1$ & $104.9 \pm 58.0^{*}$ \\
\hline Free TS & $43.0 \pm 24.4$ & $39.3 \pm 27.5$ & $42.1 \pm 32.0$ & $45.5 \pm 21.3$ & $36.6 \pm 24.2$ & $51.4 \pm 39.5$ \\
\hline$\%$ TSIR & $6.4 \pm 8.7$ & $50.3 \pm 11.4^{*}$ & $3.8 \pm 1.8$ & $58.1 \pm 17.3^{*}$ & $7.7 \pm 5.6$ & $52.0 \pm 23.9^{*}$ \\
\hline
\end{tabular}

$* P<0.05$ vs control (group A) by Student's $t$-test

Data values are means \pm SD

TS, thymidylate synthase; \% TSIR, percent TS inhibition rate

${ }^{a}$ Cisplatin was administered at the dose of $1.5 \mathrm{mg} / \mathrm{kg}$ per day 5 days $/$ week

${ }^{\mathrm{b}}$ Cisplatin was administered at the dose of $7.5 \mathrm{mg} / \mathrm{kg}$ per day on 1 day/week

Table 2. DPD activities in tumor in each experimental group after short-term anticancer chemotherapy in nude mice with SC1-NU xenograft

\begin{tabular}{|c|c|c|c|c|c|c|}
\hline & \multicolumn{6}{|c|}{ Experimental groups } \\
\hline & $\begin{array}{l}\text { Group A } \\
\text { (control) }\end{array}$ & $\begin{array}{c}\text { Group B } \\
(5-\mathrm{FU} \text { alone })\end{array}$ & $\begin{array}{c}\text { Group C } \\
\left(_{\text {cisplatin alone })^{\mathrm{a}}}\right.\end{array}$ & $\begin{array}{c}\text { Group D } \\
(5-\mathrm{FU}+\text { cisplatin })^{\mathrm{a}}\end{array}$ & $\begin{array}{c}\text { Group E } \\
\text { (cisplatin alone) }^{\mathrm{b}}\end{array}$ & $\begin{array}{c}\text { Group } F \\
(5-\mathrm{FU}+\text { cisplatin })^{\mathrm{b}}\end{array}$ \\
\hline DPD activity & $20.3 \pm 4.5$ & $12.4 \pm 3.4 *$ & $16.0 \pm 7.3$ & $11.5 \pm 4.7 *$ & $13.8 \pm 9.3$ & $8.8 \pm 5.2 *$ \\
\hline
\end{tabular}

$* P<0.05$ vs control (group A) by Student's $t$-test

Data values are means $\pm \mathrm{SD}$

DPD, dihydroprymidine dehydrogenase

${ }^{a}$ Cisplatin was administered at the dose of $1.5 \mathrm{mg} / \mathrm{kg}$ per day 5 days/week

${ }^{\mathrm{b}}$ Cisplatin was administered at the dose of $7.5 \mathrm{mg} / \mathrm{kg}$ per day on 1 day/week 
administration of cisplatin, in P388 and/or Yoshida sarcoma-bearing rats, in a dose-dependent manner. However, there are no previous studies showing a further increase in the percent TS inhibition rate in treatment with 5-FU plus cisplatin. The results of the present study demonstrated that TS did not further increase in the groups receiving combined administration of 5-FU and cisplatin, regardless of the method of cisplatin administration; this was the first demonstration of changes in TS and percent TS inhibition rates after combined treatment with 5-FU plus cisplatin. Therefore, the synergistic effects of the combination of 5-FU and cisplatin may not be attributable to a further increase in the percent TS inhibition rates. It has been shown that insufficient availability of reduced folate and FdUMP in tumor tissue is an important factor related to the formation of a ternary complex, which is the primary mechanism of TS inhibition. Although reduced folate and FdUMP in tumor tissue after the combined administration of 5-FU and cisplatin were not measured in our study, we cannot rule out the possibility that a further increase in the formation of the ternary complex may have been hampered by the insufficient availability of these factors. The other possibility to explain our findings is inaccuracy of the percent TS inhibition rate data. However, as far as variations of the percent TS inhibition rate data are concerned, the results showing no statistical significance in variations between groups with or without cisplatin would not be caused simply by technical errors of measurement.

Resistance to long-term administration of anticancer agents has been an accepted idea for the oncologist. One of the mechanisms of resistance to 5-FU is an increase in TS, because it has been shown that there are increases in TS after the administration of a 5-FU derivative [21] or cisplatin [22]. Our result showing the increase in TS after the administration of 5-FU was basically consistent with these previous reports. Furthermore, it has recently been reported that high TS protein and/or TS gene expression predicts innate resistance to 5-FU, and such factors are nominated as predictors of poor survival $[12,23,24]$. Recent reports have also demonstrated that chemosensitivity of tumors to 5FU is correlated with TS protein [12] and/or the expression of TS mRNA $[12,23,24]$. Although it is too early to conclude that TS protein and/or TS mRNA is a good indicator of chemosensitivity of individual tumors, the results of the present study demonstrated an increase TS after the administration of 5-FU, which may be related to resistance to first-line anticancer chemotherapy against gastric carcinoma [25]. Therefore, the increase in TS after the administration of 5-FU shown in the present study may provide some insight into the mechanism of the resistance to 5-FU. The increase in TS could be a good indicator for the timing of a switch from 5-
FU-based first-line to a second-line chemotherapeutic agent.

The decrease in DPD in all of the 5-FU-treated groups in our study, regardless of the combined use of cisplatin, was somewhat unexpected, and the reason for the decrease in DPD is unknown. Because DPD is the primary enzyme that metabolizes 5-FU, the induction of DPD as a catabolic enzyme for 5-FU would be expected. There are, however, no reports concerning changes in DPD after the administration of 5-FU and/or cisplatin. Recently, it has been reported that chemosensitivity to 5-FU is correlated with DPD in tumor tissues $[13,26]$. Based on these lines of evidence, a DPD inhibitory fluoropyrimidine, $\mathrm{S}-1$, has been developed, and shown to be clinically effective for advanced and recurrent gastric carcinoma [27]. Furthermore, S-1 plus cisplatin has been shown to be one of the most effective combinations for gastric carcinoma [28], and this regimen has now been widely used as first-line chemotherapy for advanced gastric carcinoma. S-1 contains tegafur, 5-chloro-2,4dihydroxypyrimidine (CDHP), and oxonate [29-31]. Tegafur is the prodrug of 5-FU [32,33]; thereby, S-1 plus cisplatin basically exerts an anticancer effect through a mechanism that is the same as that underlying the effects of 5-FU plus cisplatin. Although 5-FU combined with cisplatin is still a mainstay as the first-line anticancer chemotherapy for advanced and recurrent gastric carcinoma, repeated doses of this combination result in resistance to these agents, and the mechanism of the resistance remains to be elucidated.

Our study indicated no difference between the groups with low; and high-dose cisplatin plus 5-FU in anticancer effect or side effects, in terms of the changes in tumor-free body weight; thus, administration of low-does cisplatin combined with 5-FU had no clinical advantage over a bolus dose of cisplatin. One of the important benefits of low-dose cisplatin is the reduced incidence of toxic effects $[34,35]$, while there is no evidence that suggests that a bolus dose of cisplatin has more potent anticancer effects than a low intermittent dose [34].

In summary, combined administration of cisplatin with 5-FU did not further increase thymidylate synthase inhibition, which does not support the hypothesis that cisplatin combined with 5-FU modulates thymidylate synthase inhibition in enhancing the anticancer effect of 5-FU. Changes in dihydropyrimidine dehydrogenase after the administration of 5-FU alone and in combination with cisplatin may provide an insight into tumor sensitivity and resistance to 5-FU.

Acknowledgments This study was supported by grants from the Ministry of Health and Welfare of Japan and from Fujita Health University. The authors thank Miss Ito for excellent technical assistance. 


\section{References}

1. Schabel FM Jr, Trader MW, Laster WR Jr, Corbett TH, Griswold DP Jr. Cis-Dichlorodiammineplatinum(II): combination chemotherapy and cross-resistance studies with tumors of mice. Cancer Treat Rep 1979;63:1459-73.

2. Rooney M, Kish J, Jacobs J, Kinzie J, Weaver A, Crissman J, et al. Improved complete response rate and survival in advanced head and neck cancer after three-course induction therapy with 120-hour 5-FU infusion and cisplatin. Cancer 1985;55:11238.

3. Cutsem E, Haller D, Ohtsu A. The role of chemotherapy in the current treatment of gastric cancer. Gastric Cancer 2002;5(Suppl 1):17-22.

4. Cantrell JE, Hart RD, Taylor RF, Harvey JH Jr. Pilot trial of prolonged continuous-infusion 5-fluorouracil and weekly cisplatin in advanced colorectal cancer. Cancer Treat Rep 1987;71:6158.

5. Kemeny N, Israel K, Niedzwiecki D, Chapman D, Botet J, Minsky $\mathrm{B}$, et al. Randomized study of continuous infusion fluorouracil versus fluorouracil plus cisplatin in patients with metastatic colorectal carcinoma. J Clin Oncol 1990;8:313-8.

6. LoRusso P, Pazdur R, Redman BG, Kinzie J, Vaitkevicius V. Low dose continuous infusion 5-fluorouracil and cisplatin: phase II evaluation in advanced colorectal carcinoma. Am J Clin Oncol 1989:12:486-90.

7. Greenberg B, Ahmann F, Garewall H, Koopmann C, Coulthard $\mathrm{S}$, Berzes $\mathrm{H}$, et al. Neoadjuvant therapy for advanced head and neck cancer wtih allopurinol-modulated high dose 5-fluorouracil and cisplatin. Cancer 1987;59:1860-5.

8. Merlano M, Grimaldi A, Benasso M, Bacigalupo A, Toma S, Scarpati D, et al. Alternating cisplatin-5-fluorouracil and radiotherapy in head and neck cancer. Am J Clin Oncol 1988;11:53842.

9. Bernal AG, Cruz JJ, Sanchez P, Munoz A, Nieto A, Fonseca E, et al. Four-day continuous infusion of cisplatin and 5-fluorouracil in head and neck cancer. Cancer 1989;63:1927-30.

10. Scanlon KJ, Newman EM, Lu Y, Priest DG. Biochemical basis for cisplatin and 5-fluorouracil synergism in human ovarian carcinoma cells. Proc Natl Acad Sci U S A 1986;83:8923-5.

11. Shirasaka T, Shimamoto Y, Ohshimo H, Saito H, Fukushima M. Metabolic basis of the synergistic antitumor activities of 5fluorouracil and cisplatin in rodent tumor models in vivo. Cancer Chemother Pharmacol 1993;32:167-72.

12. Johnston PG, Lenz HJ, Leichman CG, Danenberg KD, Allegra CJ, Danenberg PV, et al. Thymidylate synthase gene and protein expression correlate and are associated with response to 5fluorouracil in human colorectal and gastric tumors. Cancer Res 1995;55:1407-12.

13. Etienne MC, Cheradame S, Fischel JL, Formento P, Dassonville $\mathrm{O}$, Renee N, et al. Response to fluorouracil therapy in cancer patients: the role of tumoral dihydropyrimidine dehydrogenase activity. J Clin Oncol 1995;13:1663-70.

14. Santi DV, McHenry CS, Sommer H. Mechanism of interaction of thymidylate synthetase with 5-fluorodeoxyuridylate. Biochemistry $1974 ; 13: 471-81$.

15. Diasio RB, Harris BE. Clinical pharmacology of 5-fluorouracil. Clin Pharmacokinet 1989;16:215-37.

16. Inada T, Ichikawa A, Kubota T, Ogata Y, Moossa AR, Hoffman RM. 5-FU-induced apoptosis correlates with efficacy against human gastric and colon cancer xenografts in nude mice. Anticancer Res 1997;17:1965-71.

17. Geran RI, Greenberg NH, Schumacher AM, Abott BJ. Protocols for screening chemical agents and natural products against animal tumors and other biological systems. Cancer Chemother Rep 1972;3:51-61.

18. Spears CP, Shahinian AH, Moran RG, Heidelberger C, Corbett TH. In vivo kinetics of thymidylate synthetase inhibition of 5- fluorouracil-sensitive and -resistant murine colon adenocarcinomas. Cancer Res 1982;42:450-6.

19. Spears CP, Gustavsson BG, Mitchell MS. Thymidylate synthase inhibition in malignant tumors and normal liver of patients given intravenous 5-fluorouracil. Cancer Res 1984;44:4144-50.

20. Diasio RB, Beavers TL, Carpenter JT. Familial deficiency of dihydropyrimidine dehydrogenase. Biochemical basis for familial pyrimidinemia and severe 5-fluorouracil-induced toxicity. J Clin Invest 1988:81:47-51.

21. Omura K, Kawakami K, Kanehira E, Nagasato A, Kawashima S, Tawaraya K, et al. The number of 5-fluoro-2'-deoxyuridine-5'monophosphate binding sites and reduced folate pool in human colorectal carcinoma tissues: changes after tegafur and uracil treatment. Cancer Res 1995;55:3897-901.

22. Kashani-Sabet M, Rossi JJ, Lu Y, Ma JX, Chen J, Miyachi H, et al. Detection of drug resistance in human tumors by in vitro enzymatic amplifications. Cancer Res 1988:48:5775-8.

23. Beck A, Etienne MC, Cheradame S, Fischel JL, Formento P, Renee N, et al. A role for dihydropyrimidine dehydrogenase and thymidylate synthase in tumour sensitivity to fluorouracil. Eur J Cancer 1994:30A:1517-22.

24. Lenz HJ, Leichman CG, Danenberg KD, Danenberg PV, Groshen S, Cohen H, et al. Thymidylate synthase mRNA level in adenocarcinoma of the stomach: a predictor for primary tumor response and overall survival. J Clin Oncol 1996;14:176-82.

25. Sakurai Y, Yoshida I, Tonomura S, Sakai W, Nakamura Y, Imazu $\mathrm{H}$, et al. Weekly administration of paclitaxel attenuated rectal stenosis caused by multiple peritoneal recurrence 8 years after the resection of gastric carcinoma. Gastric Cancer 2003;6:243-9.

26. Etienne MC, Lagrange JL, Dassonville O, Fleming R, Thyss A, Renee N, et al. Population study of dihydropyrimidine dehydrogenase in cancer patients. J Clin Oncol 1994;12:2248-53.

27. Sakata Y, Ohtsu A, Horikoshi N, Sugimachi K, Mitachi Y, Taguchi T. Late phase II study of novel oral fluoropyrimidine anticancer drug S-1 (1 M tegafur- $0.4 \mathrm{M}$ gimestat-1 $\mathrm{M}$ otastat potassium) in advanced gastric cancer patients. Eur J Cancer 1998;34:1715-20.

28. Ohtsu A, Boku N, Nagashima F, Koizumi W, Tanabe S, Saigenji K. A phase I/II study of S-1 plus cisplatin in patients with advanced gastric cancer. Proc Am Soc Clin Oncol 2001;20:656.

29. Suzuki M, Sekiguchi I, Sato I, Shirasaka T. Combined effects of S1 , a new form of oral tegafur, plus modulators on ovarian cancer in nude rats. Chemotherapy 1996;42:452-8.

30. Shirasaka T, Shimamato Y, Ohshimo H, Yamaguchi M, Kato T, Yonekura K, et al. Development of a novel form of an oral 5fluorouracil derivative (S-1) directed to the potentiation of the tumor selective cytotoxicity of 5 -fluorouracil by two biochemical modulators. Anticancer Drugs 1996;7:548-57.

31. Shirasaka T, Nakano K, Takechi T, Satake H, Uchida J, Fujioka $\mathrm{A}$, et al. Antitumor activity of $1 \mathrm{M}$ tegafur-0.4 M 5-chloro-2,4dihydroxypyridine-1 M potassium oxonate (S-1) against human colon carcinoma orthotopically implanted into nude rats. Cancer Res 1996;56:2602-6.

32. Marunaka T, Minami Y, Umeno Y, Yasuda A, Sato T, Fujii S. Identification of metabolites of 1-(tetrahydro-2-furanyl)-5-fluorouracil (FT-207) formed in vitro by rat liver microsomes. Chem Pharm Bull 1980;28:1780-95.

33. Fujii S, Nakamura Y, Takeda S, Morita K, Sato T, Marunaka T, et al. Metabolism, antitumor activity, and acute toxicity of 5-fluoro1,3-bis(tetrahydro-2-furanyl)-2,4-pyrimidinedione by oral administration to animals. Jpn J Cancer Res 1980;71:30-44.

34. Hansen RM, Ryan L, Anderson T, Krzywda B, Quebbeman E, Benson A, et al. Phase III study of bolus versus infusion fluorouracil with or without cisplatin in advanced colorectal cancer. J Natl Cancer Inst 1996;88:668-74.

35. Takahashi A, Takagi M, Hishida H, Saji E, Takagi N, Amano H, et al. The pharmacokinetics of cisplatin and its influence on renal functions based on different infusion methods. Jpn J Cancer Chemother 1987;14:2944-50. 